\title{
O que pode um arquivo feminista?
}

Resumo: Em que consiste uma ideia de arquivo a partir de uma leitura feminista? A pergunta que movimenta este ensaio surge por meio da constatação de que o termo "arquivo" é pouco mencionado dentro de uma certa bibliografia feminista, contudo a ideia de arquivo ou a ideia sobre o poder de arquivar se encontra presente em um pensamento feminista através de termos como "escassez", "sobrevivência", "memória" e "herança”. Dessa forma, faço uso do pensamento crítico e poético das autoras Adrienne Rich, Cecília Floresta e bell hooks como estudos de caso para fundamentar quais são as noções, os formatos e os tensionamentos envolvidos em uma possível ideia de arquivo feminista.

Palavras-chave: arquivo, feminismo, poesia, Adrienne Rich, Cecília Floresta, bell hooks

Abstract: In what consists an idea of archive through a feminist reading? The question that moves this essay arises from the perception that the word "archive" is not common within a certain feminist bibliography, however, the idea of archive or the idea about the power of archiving is present in a feminist thought through words such as "scarcity", "survival", "memory" and "heritage". In this way, the critical and poetic thinking of the writers Adrienne Rich, Cecília Floresta and bell hooks are used as case studies to reflect on the formats and tensions involved in a possible feminist idea of archive.

Keywords: Archive, feminism, poetry, Adrienne Rich, Cecília Floresta, bell hooks

Como elaborar um arquivo feminista? O que seria um arquivo feminista? Um arquivo feminista é um arquivo de mulheres? De quais mulheres? Quais noções estão colocadas em jogo na ideia de um arquivo feminista? São com essas perguntas que abro a investigação proposta neste ensaio. Meu interesse por esse trabalho especulativo se inicia justamente pela constatação da ausência do termo "arquivo" em grande parte da bibliografia feminista da qual tive acesso, apesar da frequente aparição de termos como "escassez", "sobrevivência", "memória" e "herança" - os quais indicam uma reflexão a respeito do poder de arquivar. Além disso, acredito que pensar em uma ideia de arquivo feminista contribui para a elaboração de políticas de leitura para recepcionar criticamente a escrita 
de mulheres e pessoas dissidentes em nossa contemporaneidade. Como um modo de responder a essas perguntas e fundamentar noções e tensionamentos presentes em uma ideia de arquivo feminista proponho um percurso de leitura entre textos e poesias escritos por mulheres e pessoas dissidentes, em especial, o pensamento teórico e poético das autoras Adrienne Rich, Cecília Flores e bell hooks.

\section{Um trabalho em torno da escassez}

Escrevo em junho de 2020, portanto, estou em casa. Quando me questiono como construir um arquivo feminista, preciso recorrer ao que tenho em mãos. Poderia, é claro, explorar acervos virtuais de bibliotecas, museus, universidades, entre outras instituições. Mas escolho como começo algo que eu possa tocar, então, pego o meu exemplar de Traduções da cultura - Perspectivas críticas feministas (1970 - 2010). Esse livro, em suas 839 páginas, talvez seja o mais próximo ao meu alcance de um arquivo feminista. Organizado por Izabel Brandão, Ildney Cavalcanti, Claudia de Lima Costa e Ana Cecília A. Lima, a publicação é produto de um trabalho acadêmico coletivo realizado ao longo de sete anos por pesquisadoras, tradutoras, editoras, revisoras e escritoras. Tal antologia de traduções de textos teóricos feministas nasce como um projeto durante um encontro do GT A mulher na Literatura realizado em 2010, na ANPOLL, sendo um grupo de trabalho que existe há quase trinta anos, e é publicada pela Editora Mulheres em parceria com a Edufal e a Editora UFSC, com apoio acadêmico e financeiro do CNPq.

No texto de apresentação de Traduções da cultura, as organizadoras explicam como esse empreendimento realizado por uma rede de pesquisadoras e tradutoras busca contribuir para os Estudos de Gênero e queer ao preencher "uma lacuna observada no tocante às produções acadêmicas em tradução” (Brandão et al. 2007: 17). Segundo as organizadoras, o trabalho de elaboração da antologia evidencia que há uma "falta de tradução de textos centrais para a história do feminismo" (ibidem). Extraio dessas afirmações um primeiro indício: talvez um arquivo feminista seja um trabalho elaborado em torno ou a partir de uma escassez, uma falta. Dois textos presentes na primeira parte da antologia - "Anos 1970: Rotas de entrada" - dialogam intimamente com essa premissa: "Infecção da sentença: a escritora e a ansiedade de autoria" e "Quando da morte acordamos: a escrita como re-visão".

Traduzido por Cíntia Schwantes e Elicene Campello, "Infecção da sentença: a escritora e a ansiedade de autoria" integra o livro The Madwoman in the Attic - The Woman Writer and Nineteenth-century Imagination, escrito pelas pesquisadoras brancas estadunidenses Sandra Gilbert e Susan Gubar em 1979. Essa obra pioneira da crítica literária feminista - que ainda não foi integralmente traduzida para o português brasileiro - analisa a literatura em língua inglesa escrita por mulheres do século XIX, como Jane Austen, Charlotte Brontë, Mary Shelley e Emily Dickinson.

Em “Infecção da sentença: a escritora e a ansiedade de autoria”, as críticas apresentam as bases teóricas que norteiam essa pesquisa. Para Gilbert e Gubar, é fundamental 
que a crítica literária feminista questione de que maneira a cultura patriarcal influencia as condições de escrita de autoras mulheres. Em busca de possíveis respostas para essa questão, elas se apropriam da teoria desenvolvida por Harold Bloom, um estudioso da psico-história da literatura que utiliza categorias freudianas para cunhar o conceito de "ansiedade da influência". Segundo Bloom, a história da literatura se desenvolve a partir da relação patrilinear estabelecida entre os jovens escritores e seus antecessores, relação essa marcada por um temor edipiano, ou seja, os "filhos" temem ser apagados, mortos, por seus "pais literários". Tal ansiedade pode ser traduzida em termos de um "excesso de arquivo": os jovens escritores homens, acuados por um acúmulo de influências, reagem com hostilidade ao vasto arquivo de seus predecessores, estabelecendo uma constante disputa a fim de superá-los.

Gilbert e Gubar apontam que a interpretação profundamente patriarcal de Bloom é interessante na medida em que seu equívoco é sugestivo. Ao resumir a história literária ocidental em uma "luta excruciante entre pais e filhos" (Gilbert/Gubar 2017: 190), Bloom (2017: 191) explicita uma perspectiva que até então se fazia presente de forma apenas subentendida, já que "analisa e explica esse fato, enquanto outros teóricos o ignoraram, precisamente, acredita-se, porque pressupõem que a literatura tem que ser masculina" (Bloom 2017: 191). É devido ao fato de Bloom enunciar essa perspectiva patriarcal que Gilbert e Gubar podem se apropriar de sua teoria da "ansiedade de influência" para evidenciar a ausência das mulheres nessa compreensão masculina da histórica da literatura e, assim, questionar qual seria, então, o lugar das escritoras em relação a esses arquivos: "Se retornamos à questão que fizemos anteriormente - onde 'se encaixa' uma escritora na história literária avassaladora e essencialmente masculina que Bloom descreve? - descobrimos que temos que responder que a escritora não 'se encaixa'” (Gilbert/Gubar 2017: 192).

É preciso comentar a sagacidade metodológica das autoras. Gilbert e Gubar escreveram essa pesquisa em 1979, um período em que a legitimidade dos Estudos de Gênero era ainda mais contestada. Dessa forma, optar pelo método de se apropriar da teoria de Bloom é também uma estratégia de defesa argumentativa. Se havia quem questionasse o efeito da desigualdade histórica de gênero na literatura, a teoria de Bloom, ao apresentar uma relação de herança literária exclusivamente patrilinear, deixava explícito o dominante apagamento das mulheres em uma compreensão patriarcal da história da arte. Assim, as autoras podem se apropriar de uma teoria desenvolvida por um homem e, portanto, menos contestada do que a maioria dos textos da crítica literária feminista, para defender o argumento de que as mulheres artistas foram historicamente silenciadas. Após ratificarem esse fato usando as próprias palavras de Bloom, Gilbert e Gubar se autorizam, enfim, a investigar quais foram as condições materiais de trabalho das escritoras de língua inglesa do século XIX.

Dessa forma, as pesquisadoras estadunidenses constatam que, enquanto os escritores se confrontam com a ansiedade de um acúmulo de influências, as escritoras, quando acessam esses mesmos arquivos, não encontram imagens ou indícios de que podem 
sequer existir, ou seja, não encontram exemplos de que é possível sobreviver na história enquanto uma mulher que escreve. Gilbert e Gubar (2017), então, desenvolvem a teoria de que as escritoras não sofrem de uma "ansiedade de influência", mas, sim, de uma "ansiedade de autoria": "um temor radical de não poder criar, de que porque ela nunca poderá vir a ser uma "precursora”, o ato de escrever irá isolá-la ou destruí-la” (idem: 193). Assim, a escassez de arquivos faz com que as mulheres escritoras estabeleçam outra relação com suas precursoras, uma relação marcada pelo profundo anseio de encontrar indícios de representatividade na história da arte. Segundo Gilbert e Gubar, esse anseio ou essa ansiedade fazem parte de uma condição psíquica da mulher que deseja ser escritora ou artista, já que, para se definir enquanto tal, precisa "procurar ativamente por uma precursora que, longe de representar uma força ameaçadora a ser morta ou negada, prova, por seu exemplo, que uma revolta contra a autoridade literária patriarcal é possível" (idem: 194).

\section{Adrienne Rich e o conceito de "re-visão"}

A crítica literária feminista seria também movida por essa ansiedade, na medida em que mobiliza uma investigação por aquelas que existiram, mas cujos arquivos não sobreviveram intactos. Portanto, escolho pensar um arquivo feminista como algo que se inicia enquanto um anseio. Como uma resposta a esse anseio, a poeta e teórica estadunidense branca Adrienne Rich propõe o conceito de "re-visão" em "Quando da morte acordamos: a escrita como re-visão", ensaio traduzido por Susana Bórneo Funck que foi originalmente publicado em 1971 no livro Feminist Literary Theory and Criticism, editado por Susan Gubar e Sandra Gilbert. Na introdução desse ensaio, Rich confronta o cânone acadêmico e literário ocidental, se posicionando ao lado das pesquisadoras, escritoras, editoras, professoras e pensadoras que ocupam as brechas desses espaços hegemônicos "compartilhando a redescoberta de obras feministas encobertas pelo tempo, fazendo perguntas de mulher, revitalizando nos dois sentidos a história e a crítica literária feminista" (Rich 2017: 64).

Dessa forma, a crítica literária feminista é compreendida como um trabalho promovido por uma rede de mulheres que disputam o espaço acadêmico tradicionalmente patriarcal e eurocêntrico, ocupando suas margens, questionando seus arquivos e propondo novas abordagens para o campo literário. É, assim, em um esforço coletivo, que a teoria e a prática feminista transformam "a disponibilidade de conhecimento" (Rich 2017: 65), ou seja, mudam a produção e a possibilidade de acesso aos arquivos sobre a vida de mulheres. Adrienne Rich situa essa transformação enquanto um despertar de consciência, algo que define como emocionante, mas também doloroso e desorientador. Talvez porque esse conhecimento reivindicado e produzido pelas mulheres da sua geração provocasse estremecimentos muito além dos aparatos teóricos, afetando diretamente suas condições de vida. Afinal, é em um âmbito de sobrevivência que Rich define seu conceito de "re-visão": 
Re-visão - o ato de olhar para trás, de ver com um novo olhar, de entrar em um texto a partir de uma nova direção crítica - é para nós, mais do que um capítulo na história cultural: é um ato de sobrevivência [...] Uma crítica radical da literatura, feminista em seu impulso, consideraria a obra prioritariamente como um indício de como vivemos, como temos vivido, como temos sido levadas a nos imaginar, como a nossa linguagem tem nos aprisionado ou liberado, como cada ato de nomear tem sido, até agora, uma prerrogativa masculina e como podemos começar a enxergar e a nomear - e, portanto, a viver - de uma nova maneira. (Rich 2017: 66-67)

Minha impressão é que re-visar é uma estratégia da crítica literária feminista a partir da qual é possível lançar um outro olhar sobre arquivos íntimos e públicos. Essa metodologia pode ser também entendida enquanto uma política de leitura. Re-visar é um modo de ler os arquivos hegemônicos questionando tanto a escassa (e problemática) representatividade de mulheres, quanto um gesto de insurgência que elabora em torno da escassez outros arquivos, dando voz às mulheres que foram apagadas, silenciadas, esquecidas, queimadas. A partir dessa impressão, reelaboro minha tese: um arquivo feminista é um trabalho em torno da escassez que re-visa, ou seja, lança um outro olhar sobre a história em busca de rastros de sobrevivência.

Adrienne Rich decide usar sua própria trajetória pessoal como exemplo do estremecimento provocado pelo despertar de consciência que movimenta seu conceito de "re-visão". Toma essa decisão não sem antes hesitar. É uma hesitação compreensível e da qual compartilho. Se implicar na teoria, recorrer a sua experiência íntima como algo que participa de sua produção de conhecimento, é contestar a pretensão de uma verdade universal e neutra imposta pelo pensamento hegemônico, patriarcal e eurocêntrico. Rich hesita porque sabe que essa escolha a coloca em risco de ser amplamente contestada. Hesita, talvez, porque, nas suas próprias palavras, o "despertar da consciência não é como atravessar uma fronteira - um passo e se está em outro país" (Rich 2017: 82). A hesitação pode ser o reconhecimento de que se localizar é marcar uma significativa recusa ao paradigma acadêmico que preza por uma falsa neutralidade.

De fato, também acredito que o conceito de "re-visão" mostra-se ainda mais potente quando o localizamos na escrita e na vida de Adrienne Rich. Em 1971, ela era uma escritora recém-divorciada, mãe de três filhos que iniciava um processo de ruptura com as influências masculinas que moldaram suas escolhas estéticas, afetivas e políticas. Em "Quando da morte acordamos", ela relata como o despertar de uma consciência política a libertou de uma vida dividida "entre a jovem que escrevia poemas, que se definia ao escrever poemas, e a jovem que se definiria por meio de suas relações com os homens" (idem: 72).

Antes de entrar em contato com as práticas e teorias feministas, Rich sentia que para ser uma escritora respeitada precisava escrever como um homem, isto é, precisava forjar uma neutralidade e silenciar suas experiências pessoais; ao mesmo tempo, para ser uma mulher respeitada precisava conduzir sua vida de acordo com as imagens de feminili- 
dade possíveis na sua época, ou seja, tornar-se uma esposa e uma mãe. A tentativa de conciliar a mulher que escreve (e que deve escrever como um homem) e a mulher que deve cumprir com os papéis sociais de feminilidade a conduz para um constante sentimento de fracasso, uma existência à deriva, sem desejo, sem êxtase e sem a liberdade necessária para uma imaginação criativa. Um trecho do ensaio "Sangue, pão e poesia: a localização da poeta” sintetiza o dilema que enfrentava nesse período de sua vida:

Eu havia nascido mulher, e estava tentando pensar e agir como se a poesia - e a possibilidade de fazer poemas - fosse um domínio universal - de gênero neutro. No universo do paradigma masculino, absorvi naturalmente ideias sobre mulheres, sexualidade, poder, da subjetividade de poetas homens - Yeats, especialmente entre eles. A dissonância entre estas imagens e os acontecimentos diários da minha própria vida exigia uma constante habilidade de imaginação, uma espécie de tradução perpétua, e uma fragmentação inconsciente da identidade: entre mulher e poeta. (Rich 2019: 138)

É quando entra em contato com as agitações políticas do fim dos anos 1950 e início dos anos 1960 que Rich começa a pensar sobre as implicações de tais acontecimentos em sua vida pessoal e, consequentemente, em sua escrita: "comecei, nessa época, a perceber que a política não era algo 'lá fora', mas algo 'aqui dentro'” (Rich 2017: 78). Tal reconhecimento é a chave que a autoriza a escrever sobre sua experiência, sobre a materialidade de sua vida como uma poeta mulher. Portanto, ao reconhecer que o pessoal é também político - um lema feminista -, Rich encontra ferramentas simbólicas para romper com a pretensão de uma poesia neutra.

A leitura de "Quando da morte acordamos" torna-se mais potente quando colocamos esse texto ao lado de ensaios posteriores de Rich, como "Sangue, pão e poesia: a localização da poeta" e "Heterossexualidade compulsória e existência lésbica”. Ambos os ensaios foram reunidos em uma antologia publicada em 2019 pela editora A Bolha com tradução de Angélica Freitas. Heterossexualidade compulsória e existência lésbica e outros ensaios é o primeiro livro que reúne os escritos teóricos de Adrienne Rich traduzidos para o português brasileiro e sua publicação foi realizada com o apoio de um financiamento coletivo (a poesia de Adrienne Rich também foi publicada pela primeira vez no Brasil apenas em 2018, na antologia Que tempos são esses?, organizada pela editora Jabuticaba).

Na introdução desse livro de ensaios, Stephanie Sauer, cofundadora d'A Bolha Editora, apresenta o impacto da leitura de Adrienne Rich em sua vida e a importância de publicar seus escritos em um momento político no qual o poder da extrema direita conservadora avança ao redor do mundo. Um trecho dessa introdução me interessa especialmente para pensar sobre a urgência de elaborar arquivos feministas como registros de sobrevivência: 
Este livro dá o pontapé inicial na novíssima série d’A Bolha Editora, que contribui com vozes novas e nem tão novas assim para discussões que estão acontecendo dentro e fora do Brasil sobre a existência, as histórias e os futuros queer. Essas discussões não são novidade, claro, mas nos beneficiamos de nos basear na nossa própria antiguidade, nas reverberações que nosso trabalho tem nos ossos de nossos ancestrais, tanto os passados quanto os futuros. (Sauer 2019: 21)

Como Stephanie Sauer aponta, a consciência de vivermos um momento político em que possibilidades estão sendo extintas pelo avanço da censura e pela perda de direitos sociais, nos alerta para a necessidade de produzir arquivos, de re-visar os enunciados criados por nossas/os ancestrais. O que me leva a perguntar quem são essas/es ancestrais? E como podemos arquivar enquanto estamos sendo (continuamente) extintas?

Mantendo essas perguntas por perto, volto à leitura dos ensaios de Adrienne Rich. Há palavras que aparecem ao longo do tempo, palavras que antes não pareciam possíveis. Em "Quando da morte acordamos", Rich comenta sua relação com os homens, seu desgaste com o matrimônio e a maternidade, indica que talvez amor, sexualidade, poder e liberdade de imaginação estejam politicamente entrelaçados, mas essa ideia não é desenvolvida. Nove anos depois encontramos a insurgência da palavra "lésbica" em um dos seus ensaios mais famosos que acaba também por enunciar dois novos conceitos, a "Heterossexualidade compulsória" e a "existência lésbica".

Publicado em 1981, em um diálogo direto com feministas heterossexuais - em geral, mulheres brancas de classe média alta que excluíam especificidades de classe, raça e sexualidade dos debates de gênero - "Heterossexualidade compulsória e existência lésbica" é um ensaio em que podemos ver o conceito de "re-visão" sendo usado como uma metodologia ou uma política de leitura feminista. Nesse texto, Adrienne Rich lança um olhar crítico sobre quatro livros de autoras feministas questionando o apagamento da existência lésbica em tais produções teóricas. A crítica de Rich (2019: 33) se baseia no argumento de que o não reconhecimento da existência lésbica "como fonte de conhecimento e de poder disponível para as mulheres" corrobora para a compreensão da heterossexualidade em termos de uma mera preferência sexual e não enquanto uma instituição política.

Após analisar criticamente essas obras feministas, Rich apresenta, a partir do ensaio "The Orign of The Family" de Katheleen Gough, as maneiras pelas quais o poder patriarcal impõe de forma simultânea a compulsoriedade das relações heterossexuais e o apagamento das existências lésbicas. Assim, elabora oito tópicos que abordam desde o controle econômico e físico imposto pelos homens às mulheres até como as mesmas sofrem da privação de "grandes áreas de conhecimento e de realizações culturais da sociedade" (Rich 2019: 47), sendo esse último ponto o que me permite refletir mais profundamente sobre a ideia de um arquivo feminista. Nas palavras de Rich (2019: 66), a queima de arquivos, "a destruição dos registros, da memória e das cartas que documentavam as realidades da existência lésbica" é parte de um projeto político heteropatriarcal que, ao 
apagar o passado, reduz as possibilidades de vida das mulheres.

Como um modo de enfrentamento à heterossexualidade compulsória, isto é, às forças estruturais que silenciam historicamente as mulheres lésbicas, Rich propõe a formulação de um novo conceito, escolhe usar o termo "existência lésbica" como uma sugestão tanto "da presença histórica de lésbicas quanto da nossa criação contínua do significado dessa existência" (2019: 65). Em outras palavras, "Existência lésbica" é um indício que une os passados e os futuros de mulheres dissidentes da compulsoriedade heteropatriarcal. Ao formular esse conceito nove anos após escrever "Quando da morte acordamos", Rich parece indicar que a "re-visão" é mais do que o ato de sobreviver, porque é também sobre construir novas condições de existência.

Portanto, enquanto uma política de leitura, a "re-visão" é uma resistência às formas de apagamento, não só como um instrumento de denúncia, mas também enquanto um gesto criativo que nos permite "começar a enxergar e a nomear - e, portanto, a viver - de uma nova maneira” (Rich 2017: 66-67). Ao acionar as práticas de re-visar e de nomear, um arquivo feminista amplia nossos vocabulários e, consequentemente, nossas possibilidades de existência. Na medida em que algumas palavras aparecem, torna-se possível enunciar situações de opressão que antes eram naturalizadas, assim como nomear formas de vida que são continuamente censuradas. Os fragmentos, as genealogias interrompidas, os restos coletados por meio desse trabalho realizado em torno de uma escassez são materiais que permitem a fabricação de ferramentas simbólicas, ou seja, de instrumentos que podem ser usados para romper com o silêncio.

\section{Cecília Floresta e a escrita de uma genealogia}

$\mathrm{Na}$ tarde em que termino de escrever sobre os ensaios de Adrienne Rich, assisto uma live em que a livreira Nanni Rios entrevista a poeta sapatão afrodescendente Cecília Floresta. ${ }^{1}$ Durante essa conversa, realizada no dia 17 de junho de 2020 no perfil do Instagram da Livraria Baleia, Floresta conta sobre seu processo de pesquisa e escrita. Eu já conhecia a trajetória de Floresta, mas, enquanto escuto mais uma vez a sua história, me surpreendo com as similaridades. Está ali a mesma frustração e a mesma fome de Adrienne Rich. Um trabalho em torno da escassez: é só depois que conclui sua graduação em Letras na PUC-SP, uma formação marcada por referências majoritariamente masculinas e brancas, que começa sua própria pesquisa em busca de uma literatura na qual possa encontrar rastros de outras experiências e usos da linguagem. De início, é um recorte amplo. Deixa de ler autores homens por um tempo e passa a priorizar a escrita de mulheres. Depois é preciso afiar os parâmetros: Quais são as mulheres que deseja ou precisa ler? É assim que inicia uma formação autodidata pesquisando o que chama de "cultura fancha", uma procura por escritoras, poetas, artistas e pensadoras sapatonas. Simultaneamente a esse projeto, ela se debruça sobre temas relacionados à ancestralidade e à negritude muito em função de sua vivência no candomblé. Essas pesquisas se transformam em oficinas criativas e ganham corpo em suas escritas. Em 2019, Floresta publica de maneira inde- 
pendente a zine genealogia, um trabalho poético que, como o título indica, apresenta uma busca por suas referências, pelos alicerces de sua escrita, algo que pode ser também interpretado nos termos de uma "re-visão". Entre esses poemas, há um em que a vontade de elaborar novas genealogias insurge de forma incendiária:

\author{
fahrenheit 451 \\ a sapatão escurinha sabe ler muito bem \\ Brecht Byron Baudelaire Maiakóvski Mallarmé \\ uns cabra assim de nome difícil \\ que mais dificultaram minha vida \\ do que inspiraram versos \\ e isso porque ocupam ainda mais linhas \\ do que deveriam \\ mas aqui eles todos cabem numa só \\ tamanho o meu cansaço \\ em inserir quebras pra separá-los ou \\ talvez uma forma de incluí-los numa mesma categoria \\ vaza da minha poesia, boys \\ quem manda rima agora é nóis
}

Penso em como essas histórias pessoais se repetem, em outro espaço, tempo e língua. A cada repetição algo se apaga e se cria. A história não só se repete, ela se complica. Os silêncios se acumulam como se acumulam os marcadores de dissidências. Entre Adrienne Rich e Cecília Floresta há distâncias consideráveis, no entanto, algo as une, talvez a escassez que continuamente aparece ou talvez o trabalho que se elabora em torno dessas faltas. Floresta não usa a palavra "despertar", muito menos "consciência", mas fala de uma "subjetividade nublada"; a função de sua escrita e de sua pesquisa é "desanuviar". Esse gesto de afastar as nuvens é pensado por ela como um trabalho a mais, um esforço a mais, o qual todas as pessoas dissidentes precisam realizar para terem acesso as suas próprias subjetividades. Para desanuviar é preciso primeiro reconhecer que há uma subjetividade nublada, ou seja, é preciso identificar as marcas deixadas pela falsa universalidade dos arquivos hegemônicos. Depois desse trabalho de ruptura, é ainda necessário buscar o arquivo que anseia encontrar, ou seja, há ainda o trabalho de elaborar um outro repertório estético e político em oposição a esse cânone.

Constituir outra genealogia talvez seja a segunda etapa de um arquivo feminista, o segundo gesto de esforço desse trabalho que se elabora em torno da escassez. A importância política da formação de genealogias torna-se mais urgente e complexa quando consideramos os diferentes lugares de fala (Ribeiro 2019), as diferentes localizações sociais, 
que atravessam a vida das mulheres e das pessoas dissidentes. Por exemplo, por mais interessante que possa ser a genealogia de escritoras do século XIX proposta por Gilbert e Gubart, esse arquivo é insuficiente para aplacar os anseios de uma jovem escritora afrodescendente e sapatão brasileira. Os parâmetros precisam se afiar de acordo com nossas distâncias sociais. A genealogia de Floresta passa por escritoras de outros tempos, línguas e lugares de fala, mas quem ela reivindica enquanto ancestral está em uma linhagem de antecessoras bem mais próxima.

Se a poesia de Floresta incendeia um cânone masculino, não o faz para reconstruir esse mesmo cânone com outros nomes femininos. Queimar esse arquivo implica, para essa poeta, restituir a literatura ao lugar de um saber ancestral. A insurgência que acompanha o gesto de desanuviar pede um outro olhar para a literatura, um olhar que não passa pela estabilidade dos formatos eurocêntricos heteropatriarcais. Em genealogia, Floresta situa sua escrita como uma prática elaborada entre sua mãe e sua avó, entre gibis e folhas secas no quintal, entre uma herança de desespero e a memória encarnada dos orixás:

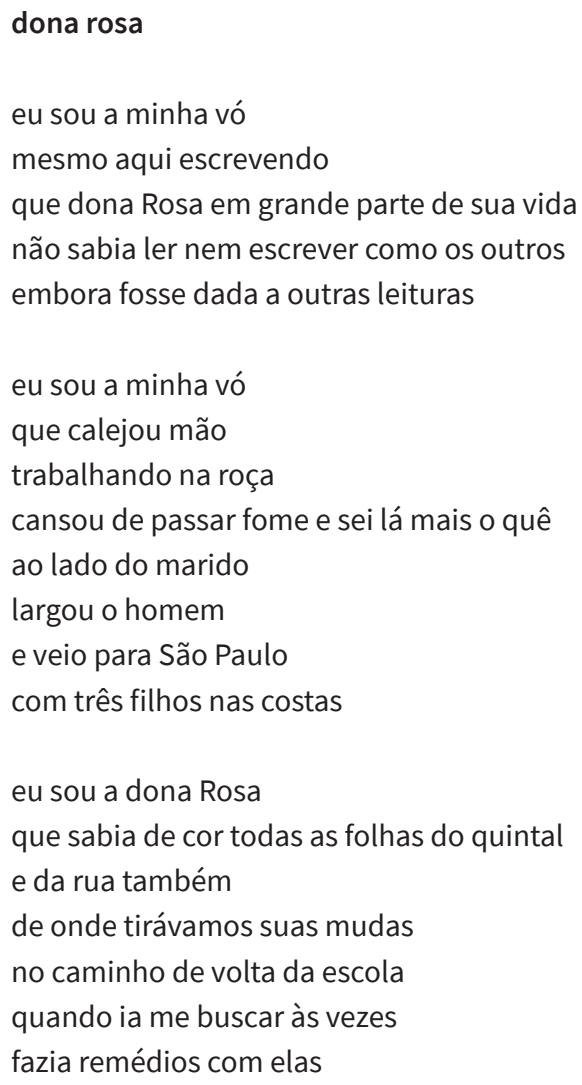




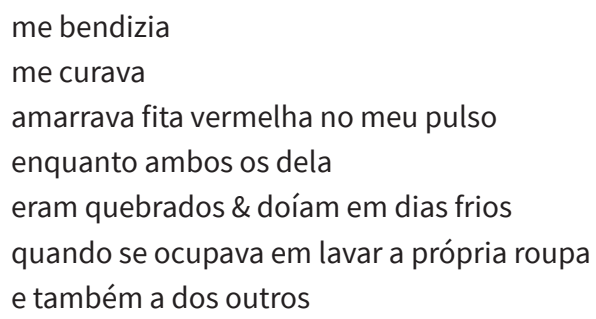

Ser, enquanto escreve, a sua avó que não pôde escrever; trazer, enquanto escreve, os ossos de suas ancestrais, seus saberes, práticas, tradições; elaborar a partir dessa genealogia novos nomes como uma herança, como uma promessa de sobrevivência. Ao elaborar sua genealogia, Floresta afirma como sua herança os saberes que não pertencem aos espaços tradicionalmente associados à produção de cultura e conhecimento. Esse é um gesto de recusa ao epistemicídio, ao projeto de embranquecimento e de exclusão de saberes que não correspondem ao formato de conhecimento que é imposto por um cânone heterocispatriarcal colonial e eurocêntrico. Uma definição interessante para esse conceito é a proposta por Heleine Fernandes de Souza em sua tese de doutorado "Poesia afro-ferminina e resistência ao epistemicídio através das poéticas de Conceição Evaristo, Lívia Natália e Tatiana nascimento": 


\begin{abstract}
Os modos de invisibilizar as mulheres negras (como cidadãs, como artistas, como intelectuais e como seres humanos) e a deslegitimação de sua autoria se revelam partes de uma mesma máquina normatizadora que mantém em funcionamento a lógica colonial, patriarcal e supremacista branca. A produção de ausências tem como resultado o epistemicídio, neologismo que remete ao genocídio de povos autóctones durante a expansão europeia e trata do apagamento de ideias que fogem ao padrão do norte global, o chamado pensamento ocidental. (Fernandes 2019: 28)
\end{abstract}

As avós, as matriarcas, são uma categoria afetiva que aparece com regularidade nos textos escritos por mulheres, sejam elas feministas ou não. Penso as avós como uma categoria afetiva, porque, ainda que cada matriarca seja evocada na singularidade de uma história pessoal, o constante aparecimento dessas antecessoras pode indicar que essas figuras que guardam o passado empenham um papel conceitual na teoria feminista. Em uma realidade de escassez de arquivos, as avós seriam algo como um arquivo possível, um arquivo ao alcance das mãos dessas mulheres que escrevem. Seriam, mas geralmente não são, justamente pelas ausências que marcam suas genealogias fragmentadas. Como uma promessa, as avós me parecem arquivos de ausências que acionam um anseio, uma busca, pelas heranças que nos escapam. As matriarcas de mulheres negras, pobres, latino-americanas, periféricas representam mais o desejo de uma memória ainda não dita do que o encontro com uma história linear e estável. Acredito que é por essa falta, por esse desencontro, que surge o desejo de elaborar ferramentas, inventar nomes e investigar percursos que possam abrandar a distância entre nós e nossas avós, ou seja, entre nós e a nossa história.

Leio em genealogias a insurgência de uma jovem pesquisadora e escritora que, ao ascender socialmente e se ver ocupando lugares de poder que foram estruturalmente negados a sua família, se recusa a se encaixar nos códigos de normatividade demandados nesses espaços. Por meio desse gesto, retomo e re-viso a questão proposta por Gilbert e Gubar: onde "se encaixa" a sapatão escurinha na história avassaladoramente racista, patriarcal e elitista que ainda vigora em nosso país? Ela não se encaixa?

Cecília Floresta parece ocupar um lugar estratégico, o que Patricia Hill Collins chamou de "outsider within" ou "forasteira de dentro". Ela circula por espaços de poder, como a universidade e o meio editorial, contudo não se encaixa em seus padrões de normatividade. Realiza, assim, uma dupla insistência: Carrega consigo um conhecimento dos arquivos hegemônicos que abrem as portas desses circuitos - arquivos que, por sua vez, nublam, embranquecem, silenciam a sua subjetividade -, mas também ocupa esses lugares trazendo os nomes, as práticas e os saberes de suas ancestrais. Esse duplo trabalho realizado por "forasteiras de dentro", por pensadoras que ocupam as margens dos espaços hegemônicos, é um esforço estratégico que possibilita uma ampliação do alcance desses arquivos, provocando estremecimentos e transformações sociais. 


\section{4. bell hooks e 0 arquivo como colcha de retalhos}

Portanto, a "re-visão" epistêmica colocada em prática por essas outsiders é um trabalho de elaboração de arquivos. Porém, quando pesquiso essas escritas de mulheres e de pessoas dissidentes não é comum encontrar esse termo, "arquivo", em vez disso as palavras que aparecem são "herança”, "legado", "memória”, "avó”. São essas palavras que se repetem no ensaio "heranças estéticas: a história feita à mão" da escritora negra estadunidense bell hooks que está publicado em anseios: raça, gênero e políticas culturais, livro lançado no Brasil em 2019 pela editora Elefante com tradução de Jamille Pinheiro Dias. Nesse texto, bell hooks - escritora que usa como pseudônimo o nome de sua bisavó marcado em letras minúscula por uma escolha política de crítica à autoridade da autoria - revisita criticamente lembranças pessoais em busca de celebrar a herança deixada por sua avó e, assim, "não mais corroborar o apagamento do legado estético e das contribuições artísticas negras" (hooks 2019: 231).

Em uma escrita na qual memória e crítica cultural caminham lado a lado, hooks propõe um conceito de estética negra em que arte e vida estão continuamente entrelaçadas. Diferentes arquivos participam da formulação desse conceito, como as colchas tecidas por sua avó Sarah Hooks Oldham, os fios de lembranças puxados por conversas com suas irmãs e o trabalho artístico de Faith Ringgold que lhe fornece "as palavras, a linguagem necessária" para escrever sobre a herança estética de suas ancestrais. É a partir do encontro com os arquivos produzidos por Ringgold, uma artista e pensadora negra que localiza a prática da tecelagem enquanto um fazer artístico, que hooks pode re-visitar sua memória pessoal e nomear sua avó como uma artista. Em contraposição ao apagamento histórico que exclui os nomes de mulheres negras da história da arte, nesse ensaio hooks compartilha os saberes, as estratégias de sobrevivência e os valores estéticos herdados de sua avó, uma mulher que não usava a palavra "arte", mas que sabia reconhecer a beleza (idem: 233).

A importância de nomear é uma estratégia que hooks aprende com sua matriarca. Quando recebia suas filhas e netas em sua casa, Sarah Hooks Oldham solicitava que suas antecessoras reconhecessem sua presença, dissessem seu nome e, depois, se apresentassem contando em detalhes suas próprias histórias: "Era como se essa longa saudação fosse um interrogatório. Para ela, era uma maneira de tomarmos ciência de nós mesmos, de estabelecer parentesco e conexão, o modo pelo qual conhecíamos e reconhecíamos nossos ancestrais" (idem: 231). Em seu ensaio, hooks coloca em prática esse mesmo gesto de nomear e, assim, tornar visíveis as formas de vida e de fazer artístico que herdou de sua genealogia familiar. É esse o trabalho de uma forasteira de dentro, trazer junto consigo o saber de sua avó e ativá-lo em uma outra prática epistemológica, no caso de hooks, a costura de sua escrita que reforça a linhagem de suas ancestrais, ao mesmo tempo em que tece novos nomes, imagens e enunciados.

Tecer colchas também é uma forma de contar as histórias. Sua avó, conta hooks, teceu por grande parte de sua vida colchas juntando restos de tecido, um estilo chama- 
do como crazy quilts, mas, quando passou a ter uma condição financeira mais estável, deixou de costurar essas colchas com fins utilitários e se concentrou em tecer colchas exclusivamente decorativas. No entanto, para hooks, os diferentes usos dessas colchas não transformavam seus valores estéticos, pois, em sua perspectiva, a estética se encontra na prática, no fazer, no movimento das mãos. Tecer colchas, para essas mulheres negras, era "um processo espiritual que ensinava sobre como se doar. Era uma forma de meditação que liberava o 'eu'” (idem: 233). Como um gesto de conexão e produção de subjetividade, a costura também elabora arquivos na medida em que a materialidade das colchas revela aspectos íntimos, econômicos e políticos que atravessam a vida de famílias ao longo dos anos:

A história estava enraizada na trajetória da colcha, no motivo pelo qual fora feita, no porquê de um padrão específico ter sido escolhido. (...) Era significativo ver Baba mostrando as colchas que fazia, contando a história de cada uma, conectando a história (o conceito por trás da colcha) e a relação dos tecidos escolhidos com a vida das pessoas. Embora não tenha chegado a terminá-la, ela começou a fazer uma colcha de pequenas estrelas com pedaços de vestidos de algodão usados por suas filhas. Juntas, examinávamos as peças e ela me contava sobre os detalhes, sobre o que minha mãe e as irmãs dela faziam quando usavam um vestido específico. Descrevia estilos de roupas e escolhas de cores particulares. Para ela, essas colchas eram mapas que traçavam o curso da nossa vida. Eram a própria história, assim como a vida sendo vivida. (idem: $240-241$ )

Ao fim do ensaio, hooks se lembra da colcha que lhe cobriu durante parte de sua vida. Esse objeto, que lhe protegeu do frio na infância e na juventude, guarda também a função de ser um mapa em que encontra pedaços de sua genealogia. Os diferentes restos de tecido, as costuras redobradas e as manchas de tinta dessa colcha contam histórias sobre quem ela foi e é. Quando ingressa na faculdade e deixa a casa de sua família, hooks escolhe levar essa colcha com ela, um gesto que, para mim, ressoa o verso de Floresta "eu sou a minha vó". Penso que a imagem de uma colcha de retalhos pode indicar um possível formato de arquivo feminista - ainda que não o único -, algo que conecta tecidos de diferentes lugares, formas, estampas e tempos. Um objeto que nos protege e nos permite contar nossas histórias.

Penso que um arquivo feminista pode se constituir como um arquivo entre mulheres, uma matéria instável que produz diferentes nomes, vivências e genealogias. 0 trabalho que se elabora a partir da escassez, então, produz uma rede, uma teia múltipla, complexa e, por vezes, dissonante - algo muito distinto de um acúmulo linear de heranças. Um arquivo entre mulheres funciona, portanto, como um utensílio e uma prática em constante "re-visão". Enquanto faço uso desse objeto e me norteio pelos seus retalhos, estou também fazendo parte da costura. Poderia continuar tecendo esse meu arquivo, puxando fios de leitura, costurando nomes de pesquisadoras brasileiras como Bianca 
Santana, Tatiana Nascimento, Jess Oliveira, Heleine Fernades, Leíner Hoki, mas, por enquanto, escolho interromper aqui minha especulação.

\section{Considerações finais: Como arquivar enquanto estamos sendo extintas?}

Durante a conversa com Nanni Rios, Cecília Floresta comenta que desde 2013 ocorreram alguns avanços no que diz respeito à publicação de autoras mulheres lésbicas e/ou negras. Nos últimos sete anos, novos nomes de poetas apareceram, traduções surgiram, editoras independentes nasceram, livros de temáticas LGBTQIA+ foram publicados e até mesmo premiados - como é o caso de Amora, de Natalia Borges Polesso, vencedor do Prêmio Jabuti em 2016. Floresta explica que ainda é pouco, mas que, sim, já se trata de uma conquista, de uma vitória. As possibilidades de enunciados foram ampliadas e as estantes das livrarias já não são as mesmas. Agora, por exemplo, é comum encontrar em algumas livrarias uma ilha exclusiva para livros escritos por mulheres geralmente acompanhadas por placas com símbolos do feminismo ou da máxima “\#LeiaMulheres" - e a falta de critério para reunir os diferentes escritos dessas mulheres sob um mesmo nicho, um mesmo marco identitário de gênero, não parece tão ruim quando lembro dos tempos em que essas escritas não apareciam porque não eram sequer traduzidas ou publicadas, como é o caso de Adrienne Rich e bell hooks.

Como uma pesquisadora e escritora que coordena a Mulheres que Escrevem, uma iniciativa literária com o objetivo de apoiar e dar visibilidade ao trabalho de mulheres, venho acompanhando de perto essa mudança de paisagem. Como Cecília, reconheço que há uma conquista nessa ampliação de possibilidades, já que muitas das minhas próprias referências não existiam em livrarias ou sebos até poucos anos atrás. Conheço o efeito que o encontro com essas escritas produzem e sei que ultrapassam o campo teórico ou literário, são mudanças em nossas formas de existência. Por reconhecer os impactos de tais transformações, frequentemente me questiono sobre as contradições desses tempos em que a insurgência de vozes de mulheres, pessoas negras e/ou LGBTQIA+, coincide com o avanço de um projeto político de extinção de possibilidades que vem tomando poder em nosso país desde 2013. Mas suspeito que essas contradições não são exclusivas do momento histórico que presencio. Conviver com a iminência da extinção parece ser uma realidade que espreita as vidas de pessoas insurgentes. Desde sempre as mulheres estão insistentemente elaborando arquivos enquanto tentam escapar de diferentes formas de silenciamento ou, como sintetiza Rebecca Solnit (2017: 96), "toda mulher que aparece luta contra as forças que desejam fazê-la desaparecer".

Extinção é a última palavra de meu projeto de mestrado escrito durante o segundo semestre de 2019, o primeiro ano do governo de Jair Bolsonaro, marcado por ataques à cultura, à educação e aos movimentos sociais. Enquanto desenvolvia a hipótese de que a poesia brasileira contemporânea escrita por mulheres demanda a produção de novos procedimentos de leitura, percebia que, para mim, recepcionar criticamente o trabalho dessas poetas era também um desejo de confrontar as forças opressoras que nos espreitam. 
A crítica seria, então, um modo de produzir, tensionar e disputar politicamente os nossos arquivos. Colocar em prática políticas de leitura feminista seria uma forma de cuidar do legado desse passado muito recente esperando que essas vozes insurgentes possam ser re-ativadas em algum momento futuro. Produzir tais práticas é, portanto, uma maneira de seguir desejando e imaginando que haverá um futuro no qual seremos sobreviventes.

Assim, retomo o conceito de "re-visão" de Adrienne Rich propondo-o como uma política de leitura. É um caminho possível re-visar esse passado ainda presente em busca das forças que tentam nos apagar. Contudo, me interessa mais apontar essa metodologia como uma prática para investigar a insurgência: quais foram as condições que contribuíram para que essas diferentes vozes de mulheres aparecessem? Quem são/foram essas mulheres? Quais são/foram suas estratégias? Quais circuitos, redes, coletivos participam desses movimentos de insurgência? Quais são as forças que nos permitem aparecer? E como podemos garantir a manutenção dessas forças? Como podemos continuar arquivando enquanto estamos sendo extintas? São essas algumas das perguntas que podem ser feitas para elaborar uma política de leitura crítica sobre a poesia feita por mulheres.

\section{NOTAS}

* Taís Bravo Cerqueira é mestranda no Programa de Pós-Graduação em Ciência da Literatura na Universidade Federal do Rio de Janeiro ( PPGCL-UFRJ) e bolsista CNPq. Dedica-se à pesquisa nas áreas de poesia brasileira contemporânea, crítica literária e teoria feminista. Integra o Laboratório de Teorias e Práticas Feministas (PACC- UFRJ). É uma das fundadores e articuladoras da iniciativa literária Mulheres que Escrevem.

** Luciana Di Leone é professora Adjunta do departamento de Ciência da Literatura na Universidade Federal de Rio de Janeiro. Jovem Cientista do Nosso Estado - FAPERJ (2019). Coordena o Núcleo Poesia - Laboratório da Palavra (PACC-UFRJ) e co-coordena o Laboratório de Teorias e Práticas Feministas (PACC-UFRJ). Atua principalmente na pesquisa de poesia latino-americana contemporânea, com especial interesse nos modos comunitários de edição e escrita. Possui Doutorado em Literatura Comparada pela UFF, com a tese "De trânsitos e afetos: alguma poesia argentina e brasileira do presente" (2011) e Mestrado em Literatura Brasileira pela UERJ (2007), obtido com a dissertação “Ana C.: As tramas da consagração”. Realizou Pós-doutorado em Teoria da poesia moderna e contemporânea na Universidade Federal de Santa Catarina.

\footnotetext{
${ }^{1}$ É importante pontuar que Floresta não se identifica enquanto feminista e como mulher. Minha leitura, a partir de uma perspectiva feminista, de sua poesia não busca enquadrá-la em tais definições, mas sim compreender como pessoas dissidentes estão contribuindo para a elaboração de arquivos contra hegemônicos.
} 


\section{BIBLIOGRAFIA}

Andrade, Antonio /Celia Pedrosa (2018), Indicionário do contemporâneo. Belo Horizonte, Editora UFMG.

Brandão, Izabel (org.) (2017), Traduções da cultura: perspectivas críticas feministas (1970 2010). Florianópolis, EDUFAL; Editora da UFSC.

Collins, Patricia Hill (2016), "Aprendendo com a outsider within: a significação sociológica do pensamento feminista negro", Revista Sociedade e Estado, v. 31, n. 1, janeiro/abril 2016. Disponível em <https://www.scielo.br/pdf/se/v31n1/0102-6992se-31-01-00099.pdf> (último acesso em: 01/07/2020).

Floresta, Cecília (2019), genealogia. móri zines, São Paulo.

Gilbert, Susan/ Gubar, Sandra (2017), "Infecção na sentença: a escritora e a ansiedade de autoria", in Traduções da cultura: perspectivas críticas feministas (1970 - 2010). Florianópolis, EDUFAL; Editora da UFSC: 188-210.

Hoki, Leíner (2020), Tríbades, safistas, sapatonas do mundo, uni-vos: Investigações sobre a poética das lesbianidades. Belo Horizonte, 2020. Dissertação de mestrado UFMG. Disponível em: <www.academia.edu/43207402/SAPATONAS_DO_MUNDO_ UNI_VOS_LE\%C3\%8DNER_HOKI_DISSERTA\%C3\%87\%C3\%830_DE_MESTRADO_ ORIENTADORA_MARIA_ANG\%C3\%89LICA_MELENDI>. Último acesso 23 de agosto de 2021.

hooks, bell (2019), anseios: raça, gênero e políticas culturais, tradução de Jamille Pinheiro Dias. São Paulo, editora Elefante.

Live Nanni Rios recebe Cecília Floresta no Instagram da Livraria Baleia (2020). Disponível em: <https://www.instagram.com/tv/CBjSotmgQsO/> (último acesso em 01/07/2020).

Rich, Adrienne (2019), Heterossexualidade compulsória e existência lésbica \& outros ensaios. Tradução de Angélica Freitas e Daniel Lümanh. Rio de Janeiro, A Bolha Editora.

-- (2017), “Quando da morte acordamos: a escrita como re-visão”, in Traduções da cultura: perspectivas críticas feministas (1970 - 2010). Florianópolis, EDUFAL; Editora da UFSC: 64-84.

Ribeiro, Djamila (2019), Lugar de fala. São Paulo, Pólen.

Solnit, Rebecca (2017), Os homens explicam tudo para mim, tradução de Isa Mara Lando. Cultrix, São Paulo.

Souza, Heleine Fernandes (2019), Poesia afro-ferminina e resistência ao epistemicídio através das poéticas de Conceição Evaristo, Lívia Natália e Tatiana nascimento. Rio de Janeiro, 2019. Tese de doutorado UFRJ. Disponível em <http://www.posciencialit. letras.ufrj.br/index.php/pt/doutorado/teses/teses-2019/258-heleine-fernandes-desouza> (último acesso em 01/07/2020). 